\title{
Classification of the Mechanical Bonds
}

\author{
Myroslav O. Vysotsky \\ Institut für Anorganische Chemie und Strukturchemie II \\ Heinrich-Heine-Universität, Universitätsstr. 1 \\ 40225 Düsseldorf, Germany \\ E-mail: m.o.vysotsky@googlemail.com
}

Received: August 22, 2011

Accepted: September 19, 2011

Published: December 1, 2011

doi:10.5539/ijc.v3n4p3

URL: http://dx.doi.org/10.5539/ijc.v3n4p3

\begin{abstract}
The analysis of suit[2]-, suit[3] ane and tetrafould [2]-rotaxanes on the bases of calix[4]- arene with the help of the "mechanical disconnection operation" show that these structures possess only one mechanical bond, which is suggested to be called bi-, tri- and tetrafurcated one, respectively, since such structures bear two, three and four divergent mechanical entanglements. In the same time, introduction of the external bulky groups to these structures transforms such unique mechanical bonds into several single ones. There can be several different invariants which have only one mechanical bond, but possess different number of the intrinsic mechanical entanglements like, for example, in [2]-catenane and doubly braided [2]-catenane. The mechanical bond in the last case is proposed to be called the tight one. The constrictive bonds in carceplexes are classified as the spherical mechanical bonds. Thus, the whole classification of the mechanical bonds (together with the previously proposed ones), is presented.
\end{abstract}

Keywords: Borromean rings, Carceplexes, Catenanes, Mechanical bond, Rotaxanes, Suit[n]anes

\section{Introduction}

The mechanically bound compounds (Balzani et al., 2009; Bogdan et al., 2006; Coronado et al., 2009; Crowley et al., 2009; Faiz et al., 2009; Godt, 2004; Harada et al., 2009; Saha et al., 2007; Sauvage et al., 1999; Stoddart, 2009) attract from year to year more and more attention not only because of their idealistically appealing structures which require sophisticated synthetic macrocyclisation methods (Wang et al., 2004; Wu et al., 2007), but also because of their feasible applications in nano-technologies (Collier et al., 1999; Green et al., 2007), material sciences (Ma et al., 2010; Tian et al., 2006) and even in bio-imaging (Gassensmith et al., 2009). The main force which contributes to the connectivity in such molecules is the mechanical bond. It rather prevents the dissociation of covalently built units than holds together in the sense of the attractive interactions (Fyfe et al., 2000). In contrast to the attention paid to the chemistry of the mechanically bound species, their correct classification in terms of different types of the mechanical bonds, still remains not sufficiently developed (Liang et al., 1994; Vysotsky, 2009).

In the previous article (Vysotsky, 2009), the tool was presented to count correctly the numbers of the mechanical bonds. It is called "mechanical disconnection operation" (MDO). It consists of three steps carried out on the link analyzed: i) cutting of a unit (sublink) within the link, ii) disconnection of the units thus obtained and iii) reparation of the unit (sublink) previously cut. The numbers of such MDOs within a given structure to finish with the structure without any mechanical bonds is equal to the number of the mechanical bonds.

However, there are special links, which possess the alternative ways for the MDOs, usually the longest and the shortest ways (Liang et al., 1994). Thus the number of MDOs on the longer way only gives the answer to the question how many mechanical bonds are present within a given link. The numbers of MDO on the longer way is also known as the so called Brunnian number M (Liang, 1994). For the topologically trivial structures like rotaxanes the complementary Brunnian number $L$ has been introduced (Vysotsky, 2009). The number of MDOs on the shortest way is known as the Brunnian number $\mu$ (Liang et al., 1994) and its complementary for the topologically trivial structures is called $\lambda$ (Vysotsky, 2009).

Let us first to analyze three examples for the demonstration how the mechanical bonds can be calculated. For instance, there are many different invariants, which all are described under the name "Borromean rings" (Liang et al., 1994). The simplest one is well known and represented with the structures of 1 shown on Figure 1 (Cantrill 
et al., 2005). There are two representations shown: a so-called reduced diagram (the number of crossings is the minimal one) and one of the alternative representations with the orthogonal positioning of the rings intertwined. Obviously, the cutting of any of the rings (or application of MDO to any of the rings) only once leads to the disconnected situation. Thus, the Brunnian numbers $M=\mu=1$. Such property is known as Brunnian property and the links which possess such property are sometimes also called Brunnian links.

In the same time invariant 2 (Figure 2), which has never been described before, belongs definitely to the class of Borromean rings. Its structure can be also analyzed with the help of MDO. In this way, the invariant 2 can be disconnected into four rings only in one step, if the first MDO is applied to the orange ring " 1 " or the blue ring "2". In the same time, if the MDO is applied to any of the green rings " 3 ", there are two disconnection operations needed to end up with the four unconnected rings. Thus, the Brunnian numbers are $\mu=1$ and $\mathrm{M}=2$. The mechanical bond between the sublink 1 and one green ring (to end up with 2 ) is the single one. In the same time, the mechanical bond in $\mathbf{1}$ is proposed to be the double one (Vysotsky, 2009). The whole number of the mechanical bonds within the Borromean ring 2 is equal to the sum $\mu+\mathrm{M}$ (but not in the structures like catenanes or rotaxanes! Vysotsky, 2009) and is equal to 3 (one triple, one double and one single).

[3]-Rotaxane 4 (Figure 3) consists of one dumbbell 5 unit and two (macro)cycles 3. In this case for the analysis we must apply the embedded graphs or rigid representations (Flapan, 2000; 2007). The number of MDOs applied to the (macro)cycles (on the longest way) is equal to two and thus the Brunnian number $\mathrm{L}=2$. The number of MDO applied to the dumbbell (on the shortest way) is equal to 1 and thus $\lambda=1$. The number of mechanical bonds within the rotaxanes is equal to $\mathrm{L}$ and thus there are only two single mechanical bonds.

In this article, the successive developments of such views on the additional structures are made and new types of the mechanical bonds are found out. This might be very important for the future work in this area, since the complexity of the interlocked or mechanically bound structures increases from year to year.

\section{Results and discussions}

\section{$2.1 \mathrm{Bi}$-, tri- and tetrafurcated mechanical bonds}

There are very interesting compounds known as suit[2]anes 7 (Williams et al., 2006), which are constructed in the way, that one unit without any cycles (body) is trapped within the second unit bearing two cycles (suit, Figure 4). If we apply the already mentioned "mechanical disconnection operation", we need only one of those to end up with no mechanically bound units. In this case the complementary Brunnian numbers $\lambda$ and $L$ are applied, since we deal with the topologically trivial structures (Vysotsky, 2009). Thus, there is only one mechanical bond in such invariant (since $\mathrm{L}=1$ ). It is however the very interesting and special one, since because of the structure, it contains two divergent mechanical intertwinings. Such mechanical bond I propose to describe as the bifurcated mechanical bond.

Analogously we can analyze the structure of the suit[3]ane 10 (Northrop et al., 2006) (Figure 5). In this case also $\lambda=\mathrm{L}=1$. Thus, there is only one mechanical bond present, which I propose to call the trifurcated one, since it has tree divergent mechanical entanglements. In the analogous way, the structure of the four fold [2]-rotaxane 13 (Molokanova et al., 2006; Figure 6) also contains one mechanical bond, which I propose to call the tetrafurcated one due to the four mechanical entanglements, which it has.

It is interesting to note, if some external voluminous groups will be attached (Figure 7), such bi-, tri- and tetra-furcated mechanical bonds will be transformed into two, three and four single mechanical bonds, respectively, since the invariants 14-16 will need two, three and four "mechanical disconnection operations", respectively, not the single ones, to completely brake all the mechanical bonds.

\subsection{Normal and tight mechanical bonds}

The additional intrinsic entanglements within, for example, [2]-catenane 19 (Figure 8) to end up with doubly braded [2]-catenane 20, does not change the number of the mechanical bonds present, however, it does change the number of the crossings present. It might also change some of the physical properties of the real molecules of such type. [2]-catenanes can be doubly (Ibukuro et al., 1999; Pentecost et al., 2006) or triply or manifold interwoven. Such mechanical bonds with the additional intrinsic intertwinings I propose to call the tight ones, not to mix them with the multiple mechanical bonds (Vysotsky, 2009), since the last ones appear within the structures having the possibility 1) to be disconnected only once; 2 ) having more than two covalent units, which are mechanically bound together. The examples on the Figure 8 demonstrate the single (19) and single tight (20) mechanical bonds.

There are also the tight double mechanical bonds possible (Figure 9). For instance, the reduced diagram of the Borromean ring $\mathbf{2 1}$ has as many as ten crossings, that is more than the usual simple Borromean ring $\mathbf{1}$ containing 
only six crossings. This means, there are additional intrinsic intertwinings present in $\mathbf{2 1}$ in comparison to $\mathbf{1}$. Thus, the mechanical bond is the double tight one in this case. In the analogous way, the tight triple, quadruple, quintuple and so on mechanical bonds are also possible and some of them are represented on the Figure 9.

\subsection{Spherical mechanical bonds}

The energetic similarity between the mechanical barriers in a pseudorotaxane and constrictive binding in a (hemi)carceplex 24 (Figure 10), had been already described (Fyfe et al., 2000). Thus, the parallels between the normal mechanical bond (which is as stable as the weakest covalent bond within a given structure) and constrictive bond (Cram et al., 1991) in a carceplex, is made. Since it is the very special bond, I suggest classifying it in the context of this article as the spherical mechanical bond.

\subsection{Complete classification of the mechanical bonds}

We could see that three new types of the mechanical bonds have been identified which complete the whole palitra of different types of the mechanical bonds: bi-, tri and tetra-furcate ones, the tight and the spherical ones. All types of the mechanical bonds are represented on the scheme shown on the Figure 11. All types can be devided in to two large groups: 1) nonpermanent mechanical bonds, which are present in kinetically not sufficiently stable complexes like pseudorotaxanes (Ashton et al., 1991; Ashton et al., 1998), hemicarceplexes (Jasat et al., 1999), anchoranes (Vysotsky et al., 2000; Vysotsky et al., 2001), foldaxanes (Ferrand et al., 2011) and 2) permanent ones, which are present in compounds like catenanes, rotaxanes, etc. The permanent bonds can be further classified into spherical ones (or constrictive) bi-, tri-, tetrafurcated, single, double, triple, quadruple and so on ones. Each of the single, double, triple, quadruple bonds can be additionally classified into the normal and the tight ones.

Thus, the classification of all types of the mechanical bonds has been successfully completed in this article.

\section{Acknowledgements}

This work was partially supported by the Deutsche Forschungsgemeinschaft (DFG, Vy6/1-3) and German State (ALG I, ALG II). The author also thanks Prof. Dr. W. Frank (Düsseldorf, Germany) and Dr. N. Ignatiev (Merck, Germany) for the current post-doctoral position.

\section{References}

Ashton, P. R., Philp, D., Spencer, N., \& Stoddart, J. F. (1991). The self-assembly of [n]pseudorotaxanes. $J$. Chem. Soc., Chem. Commun., 1677-1679. http://dx.doi.org/10.1039/c39910001677

Ashton, P. R., Baxter, I., Fyfe, M. C. T., Raymo, F. M., Spencer, N., Stoddart, J. F., White, A. J. P., \& Williams, D. J. (1998). Rotaxane or pseudorotaxane? That is the question! J. Am. Chem. Soc., 120, 2297-2307. http://dx.doi.org/10.1021/ja9731276

Balzani, V., Credi, A., \& Venturi, H. (2009). Light powered molecular machines. Chem. Soc. Rev., 38, 1542. http://dx.doi.org/10.1039/b806328c

Bogdan, A., Rudzevich, Y., Vysotsky, M. O., \& Böhmer, V. (2006). Topologically novel multiple rotaxanes and catenanes based on tetraurea calix[4]arenes. Chem. Commun, 2941-2952. http://dx.doi.org/10.1039/b601699e

Cantrill, S. J., Chichak, K. S., Peters, A. J., \& Stoddart J. f. (2005). Nanoscale borromean rings. Acc. Chem. Res. 38, 1-9. http://dx.doi.org/10.1021/ar040226x

Collier, C. P., Wong, E. W., Belohradsky, M., Raymo, F. M., Stoddart, J. F., Kuekes, P. J., Williams, R. S., \& Heath, J. R. (1999). Electronically configurable molecular-based logic gates. Science, 285, 391-394. http://dx.doi.org/10.1126/science.285.5426.391

Coronado, E., Gavina, P., \& Tatay, S. (2009). Catenanes and threaded systems: from solution to surfaces. Chem. Soc. Rev., 38, 1674-1689. http://dx.doi.org/10.1039/b807441k

Cram, D. J., Tanner, M. E., \& Knobler, C. B. (1991). Host-guest complexation. 58. Guest release and capture by hemicarcerands introduces the phenomenon of constrictive binding. J. Am. Chem. Soc., 113, 7717-7727. http://dx.doi.org/10.1021/ja00020a039

Crowley, J. D., Goldup, S. M., Lee, A. L., Leigh, D. A., \& McBurney, R. T. (2009). Active metal template synthesis of rotaxanes, catenanes and molecular shuttles. Chem. Soc. Rev., 38, 1530-1541. http://dx.doi.org/10.1039/b804243h

Faiz, J. A., Heintz, V., \& Sauvage, J.-P. (2009). Design and synthesis of porphyrin-containing catenanes and rotaxanes. Chem. Soc. Rev., 38, 422-442. http://dx.doi.org/10.1039/b710908n 
Ferrand, Y., Gan, Q., Kauffmann, B., Jiang, H., \& Huc, I. (2011). Template-induced screw motions within an aromatic amide foldamer double helix. Angew. Chem. Int. Ed., 50, 7572-7575. http://dx.doi.org/10.1002/anie.201101697

Flapan, E. (2000, 2007). When topology meets chemistry. Cambridge, Cambridge University Press. p. 2.

Fyfe, M. C., Raymo, F. M., \& Stoddart, J. F. In Stimulating concepts in chemistry; Vögtle, F., Stoddart, J. F., \& Shibasaki, M. eds. (2000). Germany, Wiley-VCh: Weinheim, 211-220.

Gassensmith, J. J., Baumes, J. M., \& Smith, B. D. (2009). Discovery and early development of squaraine rotaxanes. Chem. Commun., 6329-6338. http://dx.doi.org/10.1039/b911064j

Green, J. E., Choi, J. W., Boukai, A., Banimovich, Y., Johnston-Halperin, E., DeIonno, E., Luo, Y., Sheriff, B. A., Xu, K., Shin, Y. S., Tseng, H.-R., Stoddart, J. F., \& Heath, J. R. (2007). A 160-kilobit molecular electronic memory patterned at $10^{11}$ bits per square centimetre. Nature, 445, 414-417. http://dx.doi.org/10.1038/nature05462

Godt, A. (2004). Non-rusty [2]catenanes with huge rings and their polymer. Eur. J. Org. Chem., 1639-1654. http://dx.doi.org/10.1002/ejoc.200300503

Harada, A., Takashima, Y., \& Yamaguchi, H. (2009). Cyclodextrin-based supramolecular polymers. Chem. Soc. Rev., 38, 875-882. http://dx.doi.org/10.1039/b705458k

Ibukuro, F., Fujita, M., Yamaguchi, K., \& Sauvage, J.-P. (1999). Quantitative and spontaneous formation of a doubly interlocking [2]catenane using copper(I) and palladium(II) as templating and assembling centers. $J$. Am. Chem. Soc., 121, 11014-11015. http://dx.doi.org/10.1021/ja992391r

Jasat, A., \& Sherman, J. (1999). Carceplexes and hemicarceplexes. Chem. Rev., 99, 931-968. http://dx.doi.org/10.1021/cr960048o

Liang, C., \& Mislow, K. (1994). On Borromean links. J. Math. Chem., 16, 27-35. http://dx.doi.org/10.1007/BF01169193

Ma, X., \& Tian, H. (2010). Bright functional rotaxanes. Chem. Soc. Rev., 39, 70-80. http://dx.doi.org/10.1039/b901710k

Molokanova, O., Vysotsky, M. O., Cao, Y., Thondorf, I., \& Böhmer, V. (2006). Fourfold [2] rotaxanes of calix[4]arenes by ring closure. Angew. Chem. Int. Ed., 45, 8051. http://dx.doi.org/10.1002/anie.200602166

Northrop, B. H., Arico, F., Tangchiavang, N., Bajic, J. D., \& Stoddart, J. F. (2006). Template-directed synthesis of mechanically interlocked molecular bundles using dynamic covalent chemistry. Org. Lett, 8, 3899-3902. http://dx.doi.org/10.1021/ol061262u

Pentecost, C. D., Chichak, K. S., Peters, A. J., Cave, G. W. V., Cantrill, S. J., \& Stoddart, J. F. (2006). A Molecular Solomon Link. Angew. Chem. Int. Ed., 46, 218-222. http://dx.doi.org/10.1002/anie.200603521

Saha, S., \& Stoddart, J. F. (2007). Photo-driven molecular devices. Chem. Soc. Rev., 36, 77-92. http://dx.doi.org/10.1039/b607187b

Sauvage, J.-P., \& Dietrich-Buchecker, C. (eds.). (1999). Molecular Catenanes, Rotaxanes and Knotts. Germany, Wiley-VCH: Weinheim.

Stoddart, J. F. (2009). The chemistry of the mechanical bond. Chem Soc. Rev., 38, 1802-1820. http://dx.doi.org/10.1039/b819333a

Tian, H., \& Wang, Q. C. (2006). Recent progress on switchable rotaxanes Chem. Soc. Rev., 35, 361-374. http://dx.doi.org/10.1039/b512178g

Vysotsky, M. O., Thondorf, I., \& Böhmer, V. (2000). Self-Assembled Hydrogen-Bonded Dimeric Capsules with High Kinetic Stability Angew. Chem. Int. Ed., 39, 1264-1267. http://dx.doi.org/10.1002/(SICI)1521-3773(20000403)39:7<1264::AID-ANIE1264>3.0.CO;2-P

Vysotsky, M. O., Thondorf, I., \& Böhmer, V. (2001). Hydrogen bonded calixarene capsules kinetically stable in DMSO. Chem. Commun., 1890-1891. http://dx.doi.org/10.1039/b105613c

Vysotsky, M. O. (2009). On sublinks and their connections within the graphs of the mechanically bound molecules. ARKIVOC, (i), 289-316.

Wang, L., Vysotsky, M. O., Bogdan, A., Bolte, M., \& Böhmer, V. (2004). Multiple Catenanes Derived from Calix[4]arenes. Science, 304, 1312-1314. http://dx.doi.org/10.1126/science.109668 
Williams, A. R., Northrop, B. H., Chang, T., Stoddart, J. F., White, A. J. P., \& Williams, D. J. (2006). Suitanes. Angew. Chem. Int. Ed., 45, 6665-6669. http://dx.doi.org/10.1002/anie.200602173

Wu, J., Leung, K. C.-F., \& Stoddart, J. F. (2007). Efficient production of [ $n]$ rotaxanes by using template-directed clipping reactions. Proc. Natl. Acad. Sci. USA, 104, 17266-17271. http://dx.doi.org/10.1073/pnas.0705847104

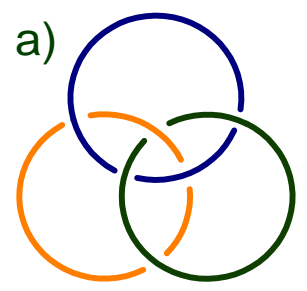

b)

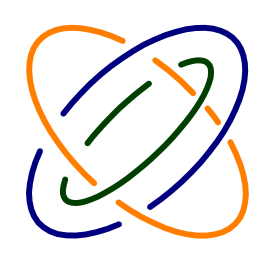

Figure 1. The simplest and well-known Borromean ring 1 in two representations: a) the reduced diagram; b) one of the alternative representations

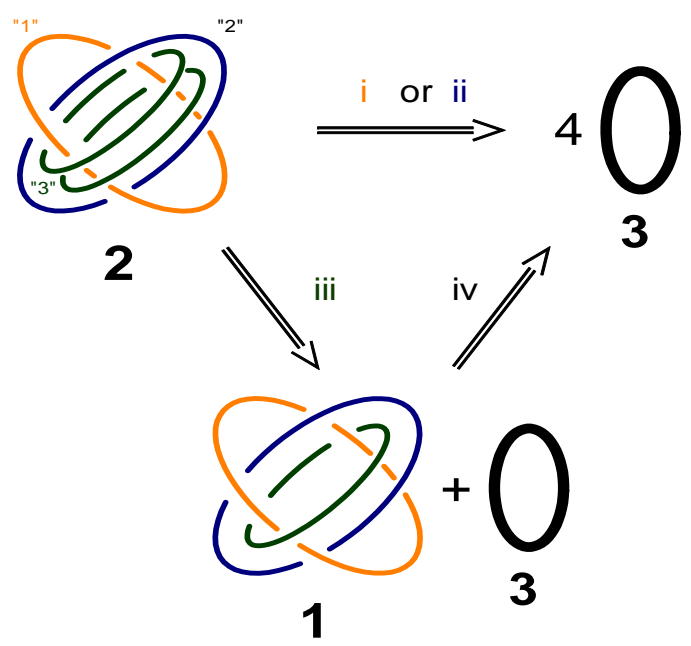

Figure 2. The mechanical disconnection of 2: i - iv are mechanical disconnection operations applied to orange (i), blue (ii), green (iii) or to any of the rings remained (iv)

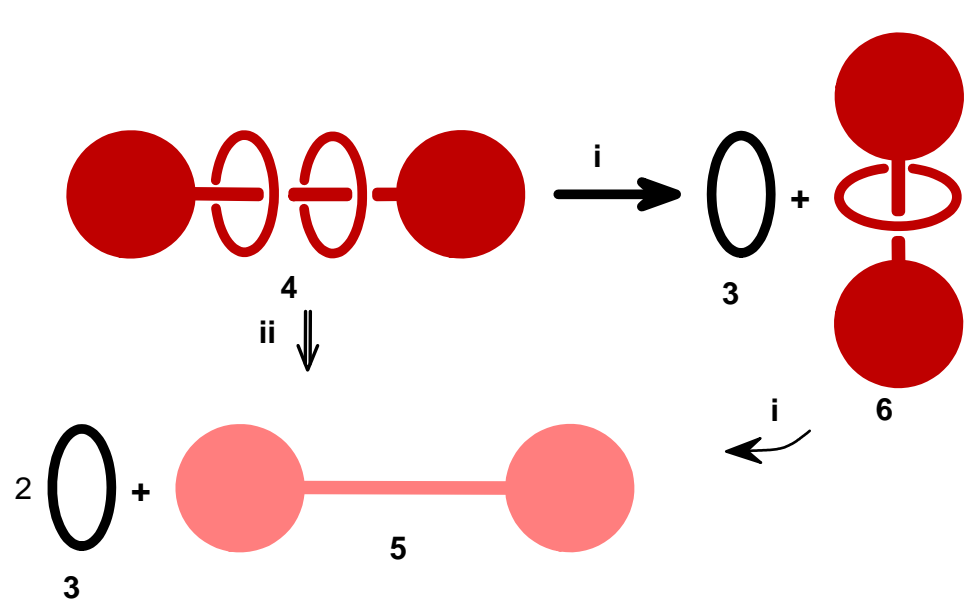

Figure 3. The mechanical disconnection of [3]-rotaxane 4. i-ii are the mechanical disconnection operations applied to the (macro)cycles (i) or to the dumbbell (ii) 


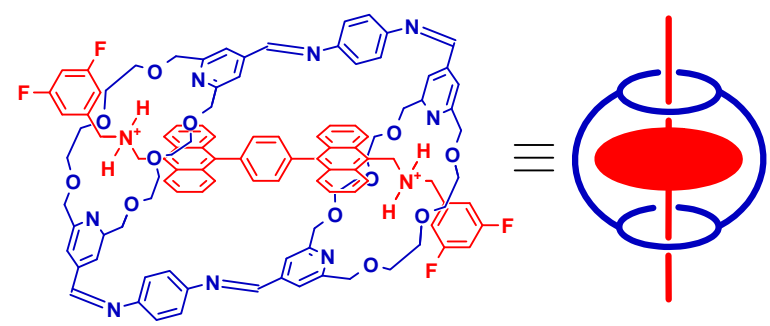

7

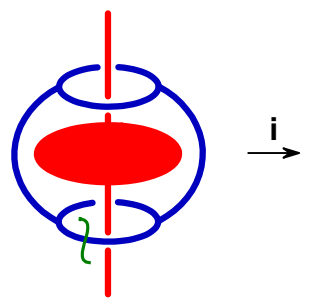

7

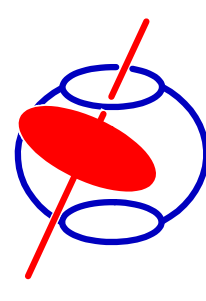

$\longrightarrow$

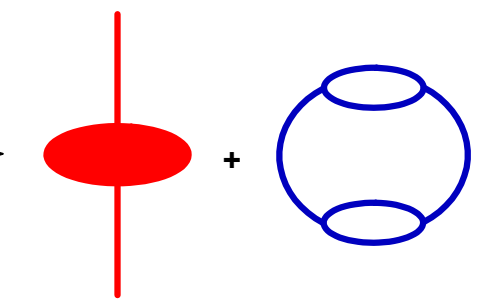

8

9

Figure 4. Structure of suit[2]ane 7. The place of the mechanical disconnection operation in 7 is indicated with the green waved line

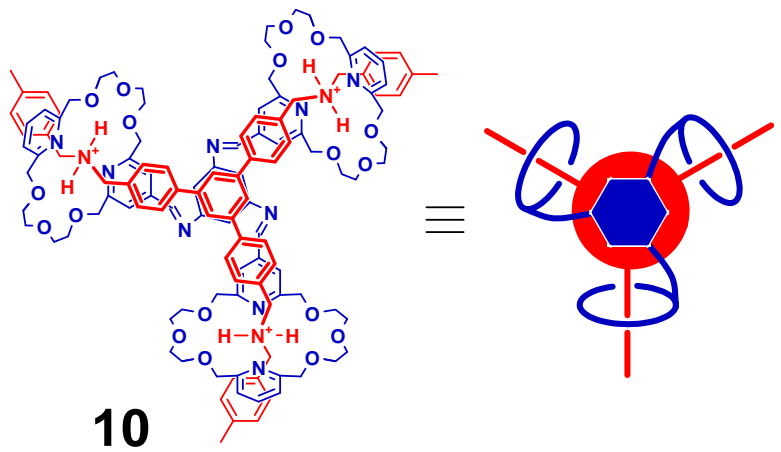

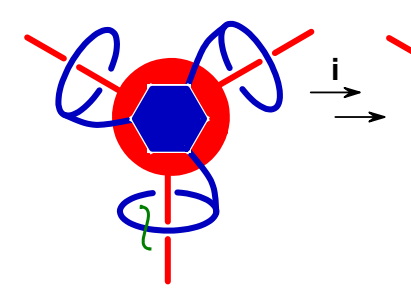

10

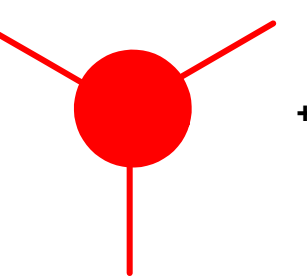

11

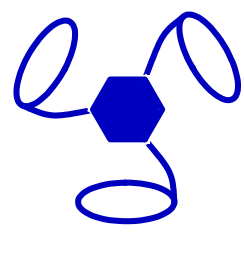

12

Figure 5. Structure of suit[3] ane 10 with one trifurcated mechanical bond. The place of the mechanical disconnection operation in $\mathbf{1 0}$ is indicated with the green waved line 

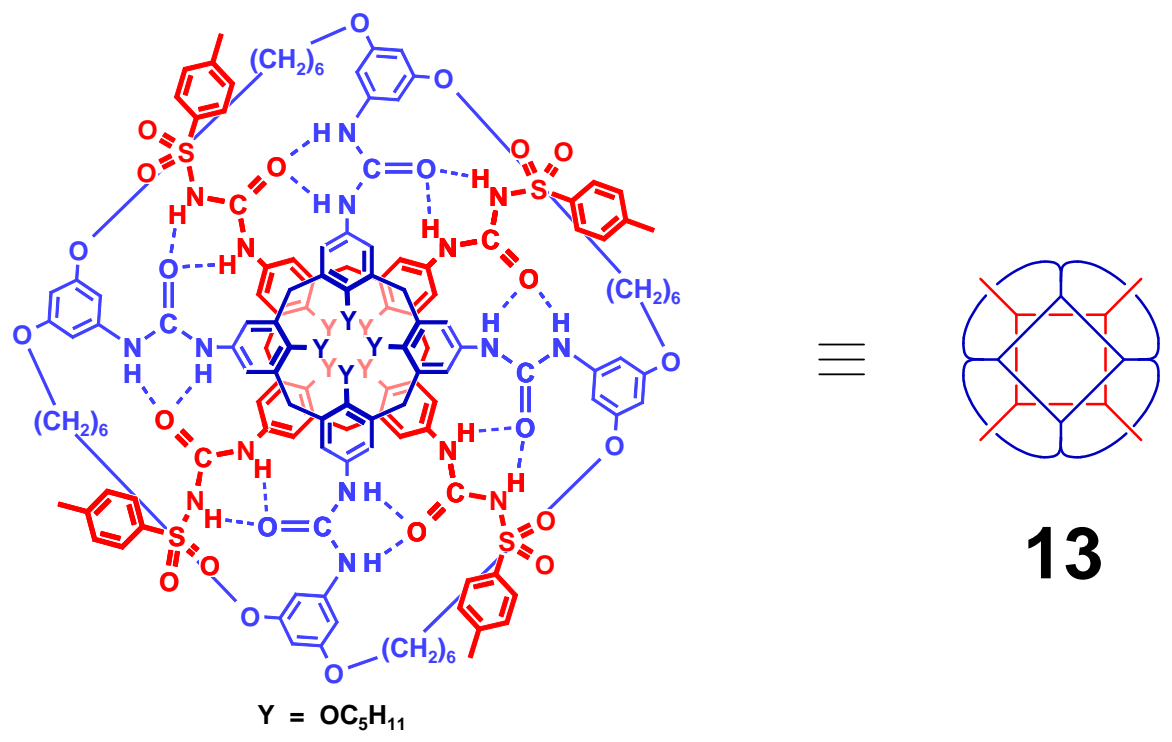

13

Figure 6. The structure of tetrafould [2]-rotaxane 13 with one tetrafurcated mechanical bond

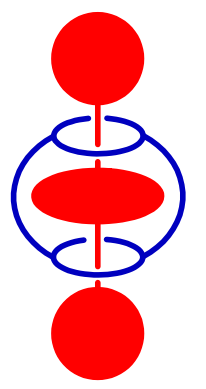

14

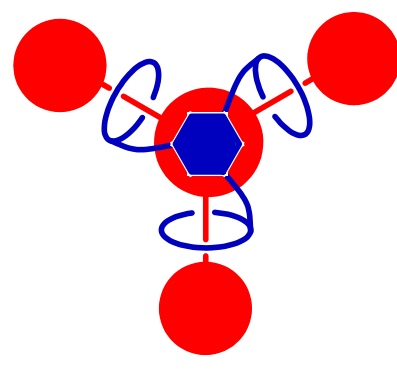

15

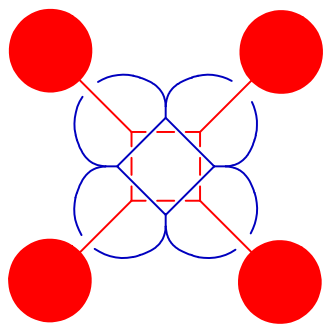

16

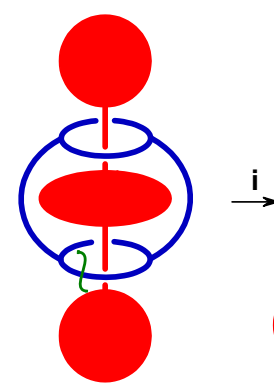

14

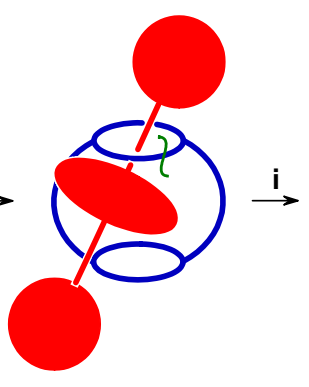

17

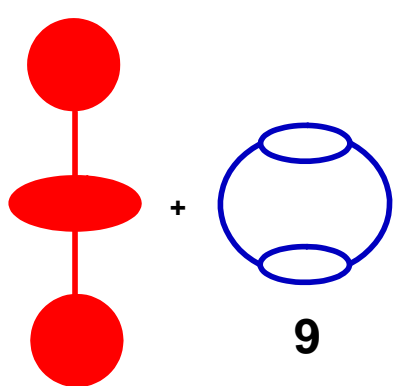

18

Figure 7. Structures 14-16 and the mechanical disconnection of $\mathbf{1 4}$. The places of the mechanical disconnection operation in $\mathbf{1 3}$ are indicated with the green waved lines 


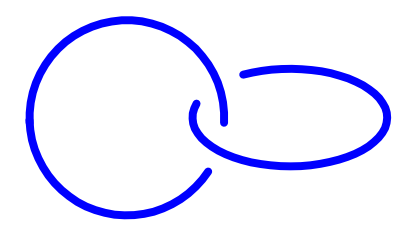

19

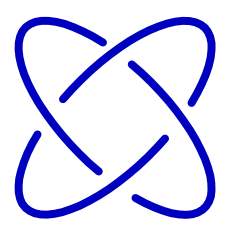

20

Figure 8. The examples of normal single ([2]-catenane 19) and tight single mechanical bond on the example of doubly interwoven [2]-catenane $\mathbf{2 0}$

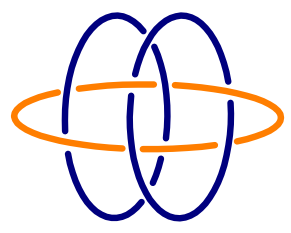

21

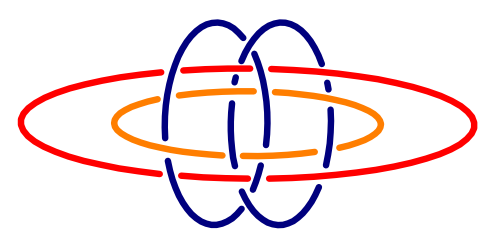

22

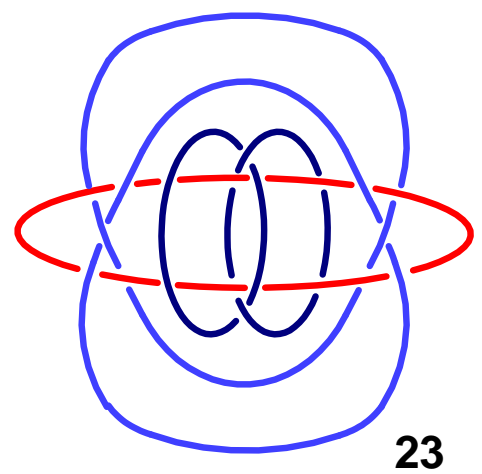

Figure 9. The examples with the tight double (21), triple (22) and quadruple (23) mechanical bonds (Liang et al., 1994)

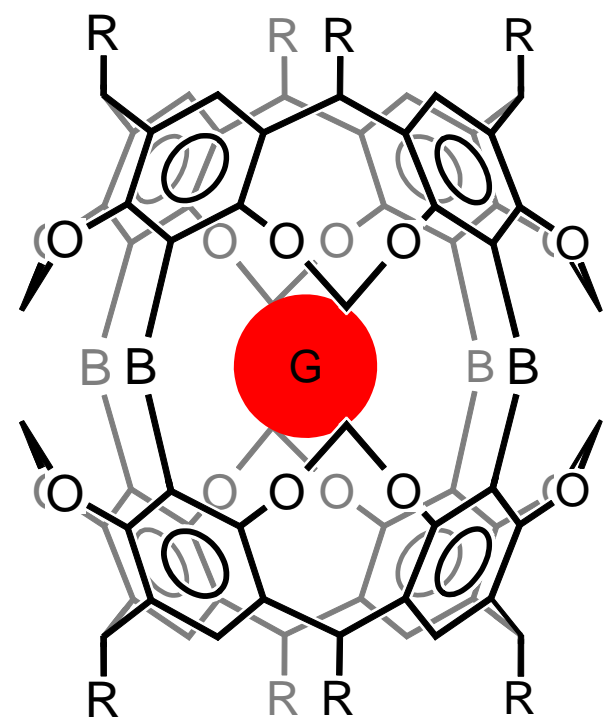

Figure 10. The general representation of a (hemi)carceplex 24. "G" is an included guest. B are bridges. $\mathrm{R}$ are the alkyl residues 


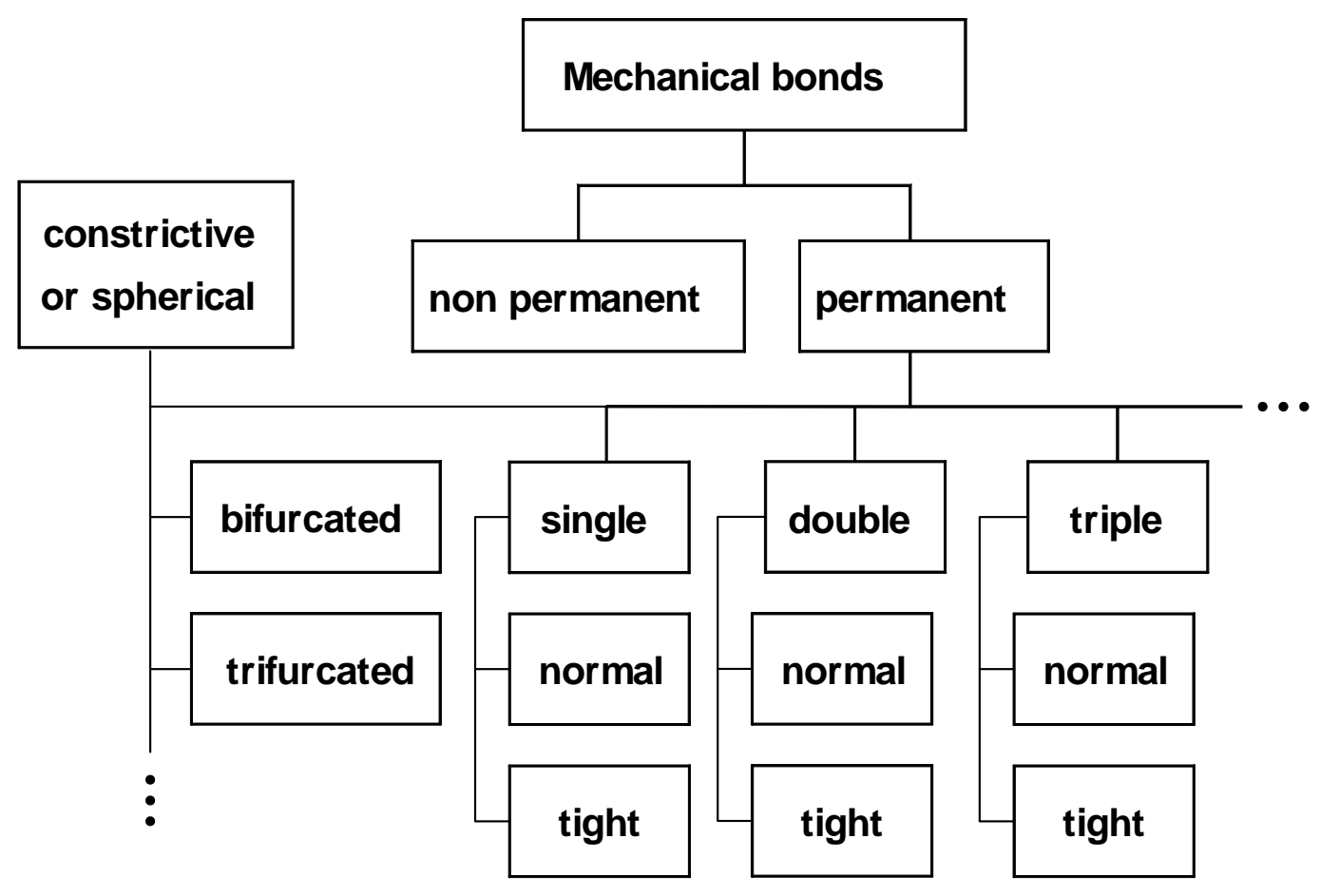

Figure 11. The schematic representation of the classification of the mechanical bonds 